\title{
The Effect of Fairclough's Approach in Iranian Literacy Texts: Critical Discourse Analysis Perspective
}

\author{
Fatemeh Azimi Amoli
}

Ph.D. Candidate in TEFL, Ilam University, Ilam, Iran

Doi:10.5901/mjss.2016.v7n4p658

\begin{abstract}
The present study was carried out to perform a validity evaluation of Fairclough approach on a poem by Akhavan Sales, called The End of the Shahname. The transferability criteria of Guba and Lincoln were utilized to transfer its results to the environment and other groups. Using the transferability criteria, the three levels of Fairclough's hypothesis, being description, interpretation, and explanation of the text, is evaluated. The purpose of this study is to answer this question; Can all three levels of Fairclough's, along with the proposed questions, been applicable in a literary text of Akhavan's poem? The results of this study represented that all sections are in line with Guba and Lincoln's emphasis on presenting maximum and rich description in order to increase transferability. Based on the trihedral model of Fairclough, in the level of representation, discourse is considered as a part of a social process. What matters here is the context knowledge. Considering all these, it can be concluded that the points emphasized by Guba and Lincoln on presenting the maximum information and descriptions in order to increase the level of transferability, it is in line with the explanation level of Fairclough model.
\end{abstract}

Keywords: Validity, Transferability, Fairclough Approach, Literary Text

\section{Introduction}

Discourse analysis, today, is an interdisciplinary orientation between humanities and social sciences. Critical discourse analysis is a new approach to discourse analysis and is deemed to be an important branch of it nowadays. In this method, both aspects of the surface and text meaning are considered. Experts such as Norman Fairclough, Ruth Vedak, Fowler and Kress have had a considerable role in introducing and also developing critical discourse analysis. In this article, Fairclough approach is chosen among many others mentioned, and it is introduced in the following.

\subsection{Fairclough Approach: Discourse as a Social Practice}

Analyzing critical discourse is a method to investigate the relationship between language and society (Fairclough, 1992). Fairlcough describes, interprets and explains texts in three levels. This method attempts to discover and explain the ideological ideas of the writers. As stated by Grant and Hardy (2004), the reason for such a choice is that, according to many scholars, Fairclough is the most remarkable theorist in this field, and his theories have been discussed thoroughly and extensively. Fairclough's approach is a kind of Textual Discourse Analysis that attempts to combine three traditions:

- Extensive and thorough text analysis in the field of linguistics (Including systemic functional grammar of Michael Halliday)

- Macro-sociological analysis of social action

- Interpretation and micro-sociology tradition based on which everyday life is considered as a product of individual's social actions.

Fairclough's discourse analysis stems from the relationship between power and language. He considers discourse to include the text and the social knowledge required to produce and interpret the text. According to Fairclough, discourse is a social practice (Fairclough, 1996). This way of thought includes a few implicit concepts: Language is a part of the society and not separate from it; language is a social process; a socially conditioned process; meaning of it depends on the other non-linguistic parts of the society (Fairclough, 1996).

The sociality of linguistic phenomena means that wherever that people use language (speaking, writing, and reading), they are affected by the society and the social conditions. When people are among their own family and away from the society, they use language based on social conventions. The second implicit concept, points out to the difference between discourse and text. In his view, each text is a product of a process which leads to the production of 
the text. Fairclough uses the term discourse to point out to the whole social interaction process, which the text is only a part of it (Fairclough, 1996).

Therefore, Fairclough considers discourse to be made of three aspects of text, discursive practice and social practice. In any communicative event, these three aspects must be considered. Fairclough draws his theoretical model in the book of Language and Power as follows:

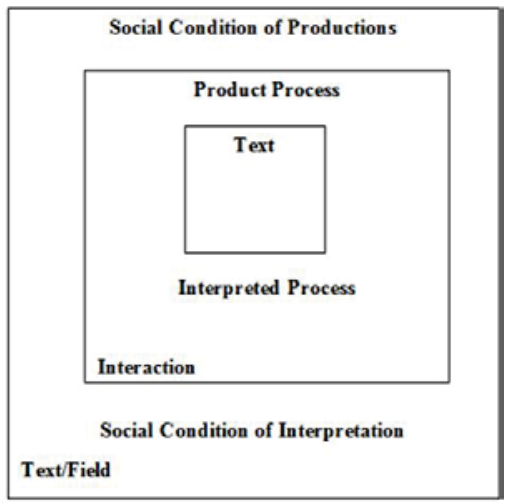

Figure 1: Three Dimensional Model of Discourse and Its Shaping Elements and the Relationship between these Elements (Fairclough, 1996).

In fact, this three dimensional model, is an analytical structure for analyzing the relationship between language and society. Any kind of communicative discourse analysis must cover the three dimensions mentioned. This model states the fact that a text cannot be understood and analyzed in a vacuum; any text must be understood in relationship to other texts and its social context.

\subsection{Investigation of Fairclough's Model Validity}

The purpose of the present study is to evaluate the validity and the implementing potential of the three levels of Fairclough approach on Akhavan's poem, which is a kind of qualitative study. There are many different measures for the validity evaluation of qualitative studies, and in this study, one of the measures stated by Guba and Lincoln will be utilized. Guba and Lincoln (1982) believe that the reliability criteria include four separate but related criterions that are credibility, reliability, conformability, and transferability. As said by Denzin and Lincoln (1994) the validity of evaluation criteria that is considered for the text of critical discourse analysis is transferability. This concept is similar to the concept of external validity. Transferability means the amount of potential of a qualitative study to be transferred to a different environment and society.

Krefting (1991) stated that transferability means that to what extent information among researcher and the text can be transferable to other contexts and other persons. In order to increase the transferability, a clear illustration of culture and the case study context, how to select, how to collect data and process analysis are significant. In addition, fruitful results and appropriate results of the findings can increase the transferability.

Transferability in qualitative research which is superseded in external validity in qualitative, means transferability of results to other research contexts with various political, social and cultural characteristics. Guba and Lincoln believed that utilizing data research in case study is an empirical process. In the contrary, some of qualitative researchers who are advocator of maximum description will utilize the following techniques to achieve the transferability:

1. Development and rich description of the collection of data during the gathering data process which can increase the potentiality of transferability.

2. Use of coding and analysis of symbols, signs in the process of data analysis which assist to transferability. (Andreas, 2003).

Guba and Lincoln (1982) believe that the researcher's responsibility is to make sure to provide adequate information on the situation and context of the study for the reader, so that the reader can achieve transferability. After 
following the extensive report on the situation of the study, the reader must understand that how much of the study and its results can be transferred to similar situations. The researcher, in order to increase the applicability or transferability of the study, must provide extensive information on the context and the environment of the study, so that the readers can be able to evaluate the amount of transferability.

According to Guba and Lincoln (1982), the researcher's task isn't to determine the indicator for transferability, but prepare the adequate data for readers to provide the possibility of indicator evaluation for transferability. The researcher has to take into consider the concern whether the observed behaviors in data are common and clear in the life of participants' behaviors permanently.

In some different veins at recent annals of literature, some other salient studies have also been carried out in CDA to dissect multiple texts and discourses and underscore multiple strategies employed by orators and authors in political, scientific, religious etc. texts in order to make the texts persuasive, significant, engaging and obscure as well as (Cap \& Okulska, 2013; Kazemian et al., 2013; Kazemian \& Hashemi, 2014 a, b; Noor et al, 2015; Ali et al., 2015; Zhou \& Kazemian (2015). Prior studies have tended to concentrate on some other genres and discourses. This study is unique in the sense that it attempts to bridge the gap among previous studies by analyzing the effect of Fairclough's approach in Iranian literacy texts through critical discourse analysis perspective.

The chosen text for this study is a literary text and one of the poems by Akhavan Sales, named "The End of the Shahname"; the discourse discipline dominant in Akhavan's poem, being one of contemporary poets, is the main concern of this study. Contemporary poetry makes up for a considerable bulk of Persian literature, and the ideological explanation of these poems in Persian literature, having an enormous share in contemporary Iranian literary culture, is of utmost importance. But this investigation, using the basic tools for causing transferability, and also using adequate description for providing all the details in the three levels of Fairclough hypothesis, which are description, interpretation and explanation, attempt to achieve a result that is related to the process of the study or deep description of the texts. And in discourse analysis, this is a proper criterion for validity of text evaluation.

\subsection{Statement of the Problem}

Most of Akhavan's validity poems are interpretable, and include codes that can lead us to the meaning by deciphering them. The pure and genuine poetry of Akhavan carries a various set of meanings, and polysemy is their prime feature, which has been shaped in poetic solitude (Mohammadi Amoli, 2001). Considering that meaning is variable and its interpretation is carried out by having the social, political and economic necessities throughout history in mind, it could be stated that appreciation of poetry requires a systematic analysis that must be history oriented and consider all the aspects of meaning-making in the text. One of these methods is the critical discourse analysis of Fairclough. This method has been one of the main strategies to analyze political, social, literary, scientific and journalistic texts in recent years. Understanding of poem requires to systematic analysis which is historical-oriented and is taken into consideration all aspects of meaning for context. One of the methods of critical discourse analysis is Fairclough's approach. This approach has recently been one of significant solution for political, social, literal, scientific and press analysis. To mention some of the studies that attempted to investigate the use of Fairclough's model in literary texts, we could name "The Effectiveness Evaluation of Critical Discourse Analysis Model of Fairclough in Criticizing Comparative Evaluation of Translated Versions of The Sisters by James Joyce" (Aghagol-Zade et al., 2010).

\subsection{The Purpose of Study}

This study aims to investigate the power relations in Akhavan's political poetry. The purpose is to answer this question; can all three levels of Fairclough's along with the proposed questions, be applicable in a literary text and properly show the relations of power? It attempts to find the poet's worldview and vision by providing a clear and proper structure, and interpreting the historical, political and social structures that are hidden in the text, and by utilizing the ciritical discourse analysis hypothesis and the analysis method of Norman Fairclough, investigate and understand the structure of language in producing texts and different layers of meaning, and ultimately, analyze all the levels of validity approach (Description, interpretation and explanation).

\subsection{Research Question}

Can all the levels of Fairclough's approach be transferable to the literary text of Akhavan Sales' poem, "The End of the Shahname"? 


\section{Materials and Methods of Research}

The data used in this study is a poem by Akhavan Sales. The overall method of the study is descriptive-analytic, in which Fairclough's approach to critical discourse analysis will be utilized. This is carried out using library study tools. The procedure is in terms of the following; in order to do a validity evaluation of Fairclough's approach in Akhavan's poem, we consider Guba and Lincoln's transferability criteria, as mentioned in the previous sections, which is possible through giving a clear definition of the target culture and context, and ultimately all the levels of Fairclough's method is applied to the text to see whether all of them (Description, interpretation, and explanation) are applicable. By investigating the level of application of all the levels of Akhavan's poem, the amount of transferability of Fairclough's approach in this Persian text is investigable. If transferability is occurred, the validity of this approach will be asserted

\subsection{Critical Discourse Analysis of "The End of the Shahname" Poem}

\subsubsection{The Poem's Title}

The End of the Shahname is a poem from a book with the same title published in 1959. Initially the poem's title, "The End of the Shahname" is investigated. The End of the Shahname refers to a proverb as: "it is the Shahname's ending that is happy". This proverb is used for those who are rash and impatient in work and want to achieve results quickly. Therefore they are advised by the wise, to do not rush, for it is the Shahname's ending that is happy.

\subsubsection{Description}

The critical analysis of this poem consists of three parts: Description, interpretation and explanation. The description part is made up of vocabulary, grammar and textual structures. In this section, experimental, expressional and correlative values are mentioned.

The first Stanza of the Poem:

This broken, out of order harp,

Tamed by the grasp of an old frenzied-colored harp,

As if dreaming at times;

Sees itself in the glorious presence of affection,

Witnessing the magnificent, gay and witnessing of Zarathustra

Or a fairy full of life,

Sees, in the clear and bright meadows of the moon;

Deceitful lights

-The caravan of dead flames in the swamp-

On the foreground of the divine altar;

The remnants of old glory, magnificence and praise.

And sings gaily;

The sad tale of exile.

In description section, experiential, relational and recitative values of words will be taken into considers.

Harp is a well-known instrument, having a bent head and a set of strings and played by the fingers. It also means as knuckles and the fingers of the hand; the palms or the fingers as if brought together to grasp something. Furthermore, it could mean as bent and curved (Dehkhoda Dictionary, Volume 17: 238).

Broken Harp

"The wine cup is the cure for broken hearts, the sun is the mummified broken moon" by Saeb Tabrizi.

In this poem, breaking is considered as a matter of ascendance. Or in another poem by the deceased Seyed Hassan Hosseini, a broken instrument sounds better:

"This instrument sounds sweeter when broken".

Ghanoon: An instrument invented by Moalem-e-Sani.

"In the presence of humanity, a drunken instrument is lowly,

The harp is out of order, and the Daf is out of hand." 
Without Ghanoon, means without order, musically false (Dehkhoda Dictionary, Volume 38: 121).

Dreaming for Someone: Thinking of a thing to do to someone (Dehkhoda Dictionary, Volume 21: 780).

Affection is one of the Aryan or Indian or Iranian pre-Zarathustra Gods. In Persian culture, Mehr (Affection) is considered as an angel responsible for kindness and friendship and the matters which are handed to him in the month of Mehr (October) and the day of Mehr. And he is also responsible for counting the rewards and punishments of human beings (Dehkhoda Dictionary, Volume 46: 182).

Shahed (Witness), literally means present, and also a witness to an act or a thing. A person, who testifies to something, is the evidence to content.

There are three types of Shahed in mysticism: The Shahed of truth, the Shahed of Ecstasy, and the Shahed of knowledge.

The Shahed (Witness) of Truth: The dominance of truth upon the heart.

The Shahed (Witness) of Knowledge: The dominance of knowledge upon the heart.

The Shahed (Witness) of ecstasy: The dominance of ecstasy upon the heart.

In the terms of Mystics, it means as what is present in the heart of man and always remembers him.

Shahed (Witness) also means as a beautiful beloved, and a handsome and charming man (Dehkhoda Dictionary, Volume 27:330).

Zarathustra is the prophet and the leader of Fire-worshippers. He claimed to be a prophet at the time of Goshtasb. Most of the Islamists consider him to be a sorcerer and a liar, but some of the contemporaries hold him in high esteem as a complete prophet and sage (Dehkhoda Dictionary, Volume 27: 330).

Zarathustra's witnessing: This adduct means that in the presence of witness, Zarathustra is present as the witness.

The experimental value lies in the lexical items and the Homayi arrangement. In the first stanza of this poem, the utilization of such words such as the Broken harp, the frenzied colored old man, as if dreaming, the splendent court of witness, the witness of Zarathustra and etc. tell a memory like dream that portray a picture of the greatness of old. This stanza of the poem is a part of the setting for the validity. This poem by Akhavan is a kind of narration, a narration told by a harp, as if it dreams of the height of Iran greatness.

The correlative value lies in the words that help create a connection between the writer (poet) and the reader. In this stanza of the poem, Akhavan utilizes words such as broken harp, frenzied colored old man, as if, dreaming, to arouse a sense of sympathy and curiosity in the reader and create the connection between the poet and the reader. Of course, the correlative value lies not only between the poet and the reader, but the correlations and relationships within the poem and the validity are also important, which will be discussed later on.

The expressive value is about the social identities and subjects. The poet, with this prologue, tells the social identity of the narrator for the reader. The broken harp itself expressed concepts that are about the subject. The harp is someone who has once had greatness and supremacy, but it has now broken and lost its tune.

The experimental aspects can be represented using some of the metaphors, and the relationship between the alternative metaphors is paid special attention to. The harp, is a symbol of the poet's esoteric and unconscious existence; and in a way, it expands to all the poets, artists, enlightened thinkers and fighters contemporary to the poet who are the honest, awake conscience and the voice of their society.

Adjectives used to describe the harp: chaotic and out of order, dreaming, drunk and prancing, telling tales and singing tunes; all are making metaphors.

The grammatical features, too, possess experimental and correlative and discursive values. The most important thing in this section is that, why among all the different grammatical structures and processes, he has chosen this particular one? Has it been deliberate? If so, what is the purpose of it?

The first stanza of the poem is about a harp dreaming, and it is followed by "as if". This "as if" emphasizes that this dream, is in fact a wish.

The Second Stanza

Capital: A city in which the monarch dwells; where the throne and the court is (Dehkhoda Dictionary, Volume 104: 12).

Century: A period of one hundred years is called a century (Dehkhoda Dictionary, Volume 38: 233).

Ghala'e: It is the plural form of castle; castles usually shaped as circles (Dehkhoda Dictionary, Volume 42: 98).

The statement "بايتخت اين كج آئين قرن ديوانه" is a beautiful combination of geography and history, and a prime example of defamiliarisation. The poet, using a kind of metaphor has considered the century as a land or a country, but has only sufficed to mention of the parts of the metaphor, being "capital".

Dr. Jalal Rahimian and Dr. Abbas Batooli Arani, in an article named "Pragmatics of Question Sentences in Poetry of Akhavan Sales", pointed out to the fact that correspondence of grammatical matters with semantic-purposeful ones 
rarely happens in both everyday language and poetic language. They have studied Akhavan's use of question sentences in some of his poetry, and have stated that the meaning of the statement mentioned before is an expression of despair and hopelessness.

The Third Stanza

(Dehkhoda Dictionary, Volume 49: 229)

In this stanza of the poem, the poet expresses certain adjectives for this century that are all an expression of hate. Adjectives such as mask-faced, bloodthirsty, dreaded messenger.

"بركنشته از مدار ماه/ ليك بس دور از قرار مهر" It points out to certain progresses made in recent years, such as the ones that have made it possible for the man to reach his old dream, to travel to the moon. Yet, in despite of all these progress and developments, there are no signs of kindness and compassion in human beings. Therefore this is symmetry of ambiguity between the words "Moon" and "Mehr".

"Morgh (bird)" is a metaphor for airplane, and this line refers to atomic bombing.

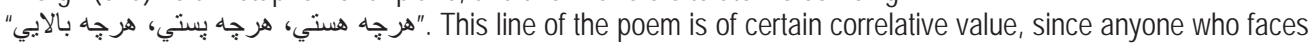
the poem is included in this definition, and his unconsciousness will be connected to that of the poet's.

"سخت مي كوبند/بالك ميروبند". There seem to be no subject for the verb of pounding.

The Fourth Stanza

ون : Laxity in work (Dehkhoda Dictionary, Volume 49: 270).

غدر: Faithlessness, betrayal (Dehkhoda Dictionary, Volume 36: 112).

The experimental values of the poem yet return to the poet's choice of words in describing the century. A shameless century that cares none for both the children and the old.

"ميدان تيغ بازى برق است روزكار بيجاره دانه اى كه سر از خاك بركثيد" By Saeb Tabrizi.

The Fifth Stanza

جكاد: It means the top of the head; the forehead. The peak of the mountain is also called جكاد (Dehkhoda Dictionary, Volume 17: 261).

اختر: One of the cosmic objects, extraterrestrials, a mobile star. The star of fortune, the star affecting one's birth (Dehkhoda Dictionary, Volume 4: 1487). 354).

هيج: No one, no person. None, the least possible amount, very little amount (Dehkhoda Dictionary, Volume 49:

There is a grammatical deviation in this line, and the actual normal sentence should be so: The spell of the silvermoon city will not fool them.

The Sixth Stanza

جكاجاك : The tune and the sound of blades and swords clashing (Dehkhoda Dictionary, Volume 17: 261).

زهر: Gallbladder, an allusion to bravery and steadfastness. زهره دران: Literally meaning one's gallbladder being cut open due to fear or another, dying from fear or another (Dehkhoda Dictionary, Volume 30: 276).

Our pronouns are of two types: Exclusive and integrative. The integrative includes the readers and the poet, while the exclusive includes the poet plus one or some others, in which the reader or readers are not included.

The Seventh Stanza

لوليان: Referring to لول, meaning shamelessness. It is also understood as gypsy and homeless (Dehkhoda Dictionary, Volume 42: 354).

\section{Eight Stanzas}

Narrator intercepts the phrase "narrated harp" in this line because the word harp has been repeated many times. The repeated word means fiasco, inability.

Tenth Stanza

Narrator used the word death three times to believe that Rostam will never come back.

يوردستان: It refers to Rostam, the son of Zal (Dehkhoda Dictionary, Volume 13: 510)

فرخزاد: Rostam, the son of Hormozd the Sixth, and one of the commanders of Yazdgerd the Third. This commander was killed by the Arab Bedouins in the Arab invasion of Iran.

\section{Eleventh Stanza}

كف: A more airy and white part of the liquid, which stays on its surface (Dehkhoda Dictionary, Volume 40: 1).

هبر: It refers to the lamb of the sheep. An allusion to someone who cannot wrong or harass anyone (Dehkhoda Dictionary, Volume 10: 989).

فرهى: Dignity, glory, greatness, magnificence (Dehkhoda Dictionary, Volume 37: 229).

F'ar, in Avestan terminology, refers to a divine truth and quality, so that when it descends on someone, it will ascend him to greatness and to levels of sainthood and divine magnificence. In other words, it brings him power, glory, 
geniality and prosperity. Ancient Iranians thought of divine F'areh as a tame animal. Divine F'areh comes to men as a tame animal and a sacred spirit, and protects them in times of need.

Koos: A great drum, dohol, or timpani, which is in fact a layer of skin drawn fast on the mouth of a great bowl.

Twelfth Stanza

Hamgenan: Same gendered, co-workers, those who are at the same level and status (Dehkhoda Dictionary, Volume 49: 296).

Torfeh: A new, pleasant, and amazing thing (Dehkhoda Dictionary, Volume 33: 217).

\subsubsection{Expressive Values in Grammatical Features}

The universality of faceted forms, in fact, tells of the existence of a clear view towards the world. As if the intended truth, shows itself to all, without struggling to decipher or uncover it (Fairclough, 1989: 198).

In The End of the Shahname, most of the sentences are used as absolute modals, and this expressed the poet's clear view and understanding of the world. Many of the sentences are positive and clear.

The archaic function of the language as one of the special features of Akahavan's poetry is mostly due to his proximity and affection to the ancient and old texts, and also his poetic wit and geniality, which has been affected by the ancient texts and Khorasan's literary circles. Archaism is one of the most effective ways of foregrounding the language and equipping it with a poetic sense; using words or structures that are no longer prevalent in everyday practice of language, or in other words, archaism refers to a continuation of the life of ancient language, throughout today's modern language.

Archaism is analyzed in two branches: 1- Vocabulary, 2- Syntax

Vocabulary: The word, "Cha'kad"

Syntax: A) Bringing the adjective with a considerable distance from the described.

"با جكاجى مهيب تيغ هامان، تيز"

B) Using an adjective as a noun.

"غرش زهره دران كوس هامان، سهر

The most prevalent causes of Akhavan turning to Archaism are:

1. Having an enormous experience regarding the old texts, and his mastery over the classic pieces.

2. An attempt to bring ancient poetry closer to "Nimayi" poetry.

3. An attempt to fully use all the potentials and beauties of the Persian language.

\section{Validity Evaluation of Fairclough's Model in Analyzing Akhavan's Poetry in the Level of Description Regarding the Transferability Criteria of Guba and Lincoln}

Based on the transferability criteria of Guba and Lincoln (1982), in order to increase the potential of transference, which means expanding the results to other structures, a clear description of the study material is required. Lincoln and Guba are advocates of maximal description, meaning that in order to reach the transferability potential, it is crucial to use rich description and coding and symbol and sign analysis. Therefore, the researcher must provide a vast range of information on the structure of the study so that the reader can be able to evaluate the amount of transferability.

On the other hand, based on Fairclough's hypothesis, in order to describe a text, the vocabulary (Their experimental value, semantic and ideological relationship between the words, correlative values, them being formal or colloquial, expressive values and the way metaphors are used), grammar (The experimental value of grammar components, processes and control participants, existence of an unknown activist, the process of noun-making, using active and passive sentences and positive and negative sentences, the expressive values of grammar components, the relationship between the words, using linking words and the way of using complex sentences and reference utilities) and textual structures (How to use interactive contracts) must be analyzed. In order to increase transferability, which is accessible through rich description, we thoroughly discussed the different components in the previous part. For example, the experimental value of the words and their collocation was investigated in the poem, which expressed the imagery made by the poet of a broken harp, lamenting his loss of greatness of old. The harp is a symbol of the enlightened poet's unconsciousness that has been fed up with his own time, and expresses his hopelessness of a century with enormous technological advancements but no advancement in kindness by using question sentences.

Therefore, it appears that the first part of Fairclough's model, being word description, grammar and textual structures, is in line with Guba and Lincoln's emphasis on maximal and rich description in order to increase the level of transferability. In other words, as much as one would be able to give a rich and deep description of the cultural structure 
and lexical, grammatical an textual structures of the poet, there is just as much potential to realize the term "thick description" of Guba and Lincoln and consequently create an even more possibility for transferability.

\subsection{Interpretation}

In this section, the reader, initially, receives the surface meaning of the words based on his language competence, consisting of phonetics, vocabulary and grammar. The next part is giving meaning to this surface of the words. In this section, the reader uses semantics and pragmatics. In the next section, a semantic relationship is formed between the sayings (Topical Coherence). Then the text is analyzed through a comprehensive cohesion.

The relationship is formed in two ways: Verbal (Relating words and repetition words) and lexical.

Verbal relationship using relating words is rather rare in this poem.

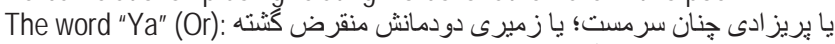



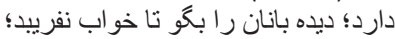

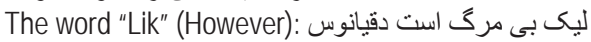

The word "Va" (And): This word has been repeated quite more than the others, such as: ناله و مويد/ مويد و كورئ

The word "Agar" (If): ور زمين گهو اره فرسوده آفاق

\subsection{The Repetition of Words}

The repetition of words such as Chang (harp), Gharn (century), and Ma (us), in the various lines, has made this poem coherent. However, the existence of pronouns in the verbs, which point out to the subject in a few lines back, have had a considerable effect in the coherence of this poem. The essence of The End of the Shahname is a lament; a compliant for the century the poet lives in; a lament for a dream which recalls the glory of Iran. The reader, based on his literary potency, and his expectations from New Persian poetry, will not only be able to identify the poem with one of the current discourses, but will also absorb and remember the essence of it for time to come.

Following this stage, the situational and intertextual texture will be utilized in order to interpret the text. The following questions are proposed in the situational texture: story?

What is going on? Who are involved? How are they related? And what is the role of language in progressing the

The story is about a broken harp, which remembers the glory and magnificence of the ancient times and seeks to conquer the contemporary century; the century in which man as progressed scientifically and industrially, but moral values have given their place to vices. And any attempt to rebuild this ruin is futile.

This narrative poem seeks to point out to four things in a theatrical way: 1- The dream of ancient Iran's glory; 2The illusion of overcoming the hardships; 3- Self-awareness and opening one's eye to the reality of the time and confessing to futility of any attempts to undo it; 4- Complete submission to despair and frustration.

The harp is a symbol of the esoteric existence and unconsciousness of the poet and in fact all poets, artists and enlightened non-conformists of the poet's time, who are the honest representatives, awake consciousness and the voice of their society.

In this narrative, the harp, the contemporary man, the events of the contemporary century, and the glory of ancient in Iran, are all concepts involved in the matter. The harp, being the narrator, tells of the glories of ancient Iran and complains about the vices of the contemporary period, and confesses to his helplessness in altering the situation. The poet, by referring to archetypes, first escapes from the norms of everyday language towards a literary language, which is one of the main features of art in poetry, and secondly, by using these archetypes, has given such strength to his lines that recall the glory of ancient times, and using this language in order to progress the ideas in a text is considerably unique. In this poem, the role of the particular language used is to express the lost glory and magnificence of Iran, and considering the suffocating environment following the coup of $18^{\text {th }}$ of august of 1953; the poet has had no choice but to use a symbolic language to express this.

Following this stage, the interpreter, must determine the subjective environment based on "the social aspect of social order". The subjective environment of the poets is an environment built by the old poets and critics of Persian language, and one can only alter this subjective environment if they first, have a total mastery over it, and secondly, be regarded with a high degree of dignity and greatness. Any major changes in this environment require the passing of time and the involvement of poets in this change. Of course, a definition of this environment is acquired quite unconsciously by the users of the language, and alongside learning the language; a discourse-based literary competency takes shape. In 
our case, the position of poet and poetry in literature has been previously defined for the reader, and the poet can only attempt to cause a change using this definition. In fact, a poet, on his own, cannot change much in a discourse already defined. Yet his subjective environment includes various situations, which the poet and the reader are partially aware of, and we know it as the discursive order. In the next stage, the interpreter binds the poem, being a kind of a social practice, to one of these situations. The act of defining the type of discourse and the situation is simultaneous. And this is so that the interpreter analyzes the text from the very beginning. For example, the reader is aware of the whereabouts of the poet, the time of the poem and of the air of the rest of poets and poetry in general, and this is one way to understand the poem. However, the type of the situation is defined by the social order or discursive order; meaning that with a change in the social order, the situation which is the basis of the definition, will change, and it even might be that with a change in the dominant government, the poem might be understood in a way completely contradictory to that of the initial understanding.

The intertextual texture is considerably related to this that the text must be attributed to which collection; thus the presumptions common between the reader and the writer become peculiarly important to us. Presumptions and common grounds are not exclusive features of the text. Considering that this poem has been written in the Mehr (September) of 1957, meaning a while after the coup of 1953, the presumptions for the audience of this poem would be a suffocating environment in which tyranny, despair, hopelessness and the loss of dreams are prevalent.

\subsection{Discursive Acts}

In this case we can consider the discursive acts in each line of the poem, or consider the discursive act of the whole poem as one. In reality, the discursive acts in the poem are utterly sad; hopelessness, despair being a few.

One of the common knowledge is the foundation of abstract schemes, which is of considerable quality and utility when trying to interpret and understand a social practice. But it must be considered, that one of the main components of poetry is the abstract structure of it, and this feature, especially in New Poetry, will cause the piece to not have an exact foundation of abstractness. A lack of a particular foundation is peculiar matter which the users of a language learn it during their education as literary competence. In fact, a user of Persian language has learned to tolerate the abstract structure and ambiguities in Persian poetry and look for alternative answers for a poem. However, this does not mean that New Poetry lacks structures, but conveys that one cannot consider a whole abstract foundation for the poem and expect the poet to use this structure in his craft, and the same for the reader in the process of understanding. In fact, each Persian poem requires a particular foundation and imaginative structure to be unique.

The point is that the language of the poem does not point out to the social structure, but instead is a reference to an imaginative world made in the mind of the poet or the artist, and in most cases, the language user has no choice but to memorize the whole poem to remember this imaginative world, since each word of the poem is a gateway to this world. Therefore, the foundation and structure of Persian poetry is not like that of a news column or a bureaucratic letter, which would already be there in the mind of the reader in order to help understand the text. The users of Persian language, considering their literary competence, have found out what are the differences between a literary text like a poem and a non-literary text such as a news column, and when reading a poem, they do not seek to comply the poem to the real world, but only utilize the similarities this imaginative world has with the real one.

\section{Validity Evaluation of Fairclough's Model in Analyzing Akhavan's Poetry in the level of Interpretation Considering the Transferability Criteria of Guba and Lincoln}

Considering the transferability criteria of Guba and Lincoln, providing the maximum information and presenting rich descriptions in order to the increase the potential for transferability, clear explanation of culture and the field of study are absolutely necessary. Guba and Lincoln believe that the responsibility of the scholar is to make sure that enough information is provided for the reader regarding the situation and the texture of the study, so that transferability can be achieved. Utilizing Fairclough's model in Akhavan's poem, The End of the Shahname, it was concluded that providing these rich and deep descriptions can create the field for a more potent transferability, which according to Guba and Lincoln, is one of the necessary conditions to validly realize the study. For instance, in the second level of Fairclough's model, interpretation, initially the word is obtained through the vocabulary knowledge and then this word is given meaning to. Furthermore, a partial cohesion and then a comprehensive cohesion is made between the words. In the investigation of Cohesion it was concluded that cohesion in this poem is achieved through repetition. For example, the repetition of words such as harp and century in various stanzas and also the existence of pronouns in the verbs have had considerable influence in the cohesion of this poem. 
The comprehensive cohesion of the text is a lament on the time of the poet which the reader, considering his/her historical and literal competence can sympathize with. On the intertextual texture and interpretation of it, as it was mentioned before, the story is about a broken harp who as the narrator tells of the glories of ancient Iran and complaints of the vices of the contemporary century and expresses his helplessness in altering this situation. In this poem, the role of the language is to express the lost glory of Iran, which considering the post-coup suffocating environment of august 1953, leaves the poet with no choice but to use a symbolic language. In the next level, the interpreter links the poem to one of the situations, since the poem is a kind of a social practice. Considering the fact that this poem has been written in the September of 1957, meaning only a few years after the coup, the presumptions of the poem are the glory of ancient in Iran, man's exploits of scientific progresses, the confusion of man in finding and realizing his dreams, unawareness of previous generations in preserving an safekeeping of this glory, the poet's relentless attempts to mend the situation, the futility and defeat of any reforming attempts and the its repetition in the course of history, and the immortality of the Pharaoh of the time. As it was said about the discursive acts; some of them are despair, hopelessness and frustration.

Therefore, it was determined that in the level of interpretation, Fairclough's model is in line with the transferability criteria of Guba and Lincoln, which are achieved through presenting details and rich textural information such as cultural, social and political information.

\subsection{Explanation}

The purpose of this stage is to describe discourse as a part of a social process:

A) How do social structures determine a discourse?

B) What reproductive effects does discourse have on social structures?

What is considerably important here is the underlying knowledge, since this is what mediates these changes.

How to determine the discourse of the poem is an act that requires further research, and what can be said about Akhavan's poem is that his life was in a period that political movements seeking to reform the country were at the peak of their activity, and Akhavan himself was also a participant in one of these political groups and was, for the very same reason, imprisoned twice in his lifetime. He was placed in a period that he had witnessed the experience of Constitutionalist movement poets and at the same time drew inspiration from the older poets and combined the Khorasani style with the new Nimayi style, and created immortal pieces in Persian language. Now, regarding the concept of discourse, we will analyze these social structures. The most important of social structures in determining the discourse of New Poetry are:

A) Continuing the political campaigns against the Monarchy that has started from the period of Constitutionalists.

B) Transforming New Poetry to the language of the enlightened and utilization of fighter poets of this language to raise awareness among the people.

C) The assignment of poets as the protectors of liberty and thinkers whose chief concern were the people. However, this was in its own turn inspired by the history of poetry in the previous generations.

\section{Validity Evaluation of Fairclough's Model in Analyzing Akhavan's Poetry in the Level of Explanation Considering the Transferability Criteria of Guba and Lincoln}

Based on the hypothesis presented by Guba and Lincoln, providing background information can help to present rich descriptions of the investigated phenomenon, so that the reader is able to obtain a correct understanding of them and compare the samples of these phenomenon described in the study with those in his/her own life.

On the other hand, based on the trihedral model of Fairclough, in the level of explanation, discourse is considered as a part of a social process. In this case what is important is background knowledge. What can be said about Akhavan is that his life was in a period that political movements seeking to reform the country were at the peak of their activity, and Akhavan himself was also a participant in one of these political groups. He had witnessed the experience of Constitutionalist movement poets and at the same time drew inspiration from the older poets and combined the Khorasani style with the new Nimayi style, and created immortal pieces in Persian language. The most notable of social structures in his poetry are the continuation of political campaigns against the monarchy, transforming New Poetry to the language of the enlightened and the assignment of the poets as the protectors of liberty.

Considering the statements above, it can be concluded that the points emphasized by Guba and Lincoln's hypothesis on presenting maximal information and description in order to increase transferability is in line with Fairclough's level of explanation model. In the level of explanation, any communicative event is of a social reality of its own. The point is to highlight that the discourses present in the text have been shaped from social ideas and textures. 
Such an attempt for determining external and social realities such as what is in the text can help the reader to obtain a proper understanding of them and compare the described phenomenon with those present in his life.

The validity of Fairclough's trihedral model of discourse analysis was carried out in this poem by utilizing the transferability criteria of Guba and Lincoln which is done through rich description and deciphering of the vocabulary and the symbols, and it was shown that in all the three levels, Fairclough's model does meet the maximal description criteria expected by Guba and Lincoln.

Validity of trihedral model of fairclough, (description, interpretation and explanation) in this poem is feasible based on Guba \& Lincoln's transferability criteria through thick description and lexical decoding and symbols and has been displayed that the maximum description in Fairclough model in three levels based on Guba and Lincoln has been provided and involved.

\section{References}

Aghagolzadeh, F., Arjmandi, M., Golfam, A., Kord, K, Aliyeh. (2010). Validity Pattern of Faiclough's Critical Discourse Analysis in the review of equivalents in translated Texts called "Sisters" written by James Louis. Language Researches and Comparison Literature, 1 (2).

Akhavan Sales, M. (1990). Ghozineh Asha'r. Tehran, Morvarid Publication.

Ali, S. \& Kazemian, B. (2015). Critical Discourse Analysis of a Reading Text 'Pakistan and the Modern World': a Speech by Liaquat Ali Khan. Communication and Linguistics Studies, 1(3), 35-41.

Ali, S. \& Kazemian, B. \& Bughio, F.A. (2015). An Investigation of a Reading Texts 'Pakistan Zindabad' (Long Life Pakistan): Critical Discourse Analysis Perspective. Education and Linguistics Research, 1(2), 42-51. Doi: 10.5296/10.5296/elr.v1i2.81

Andreas, M. R. (2003). Validity and reliability tests in case study research literature review With " hands-on application for each research phase, Qualitative Market Research: An International Journal, Volume 6, Number 2, pp.75-86, Griffith University, Nathan, Australia.

Cap, P., \& Okulska, U. (Eds.). (2013). Analyzing Genres in Political Communication: Theory and Practice (Vol. 50). John Benjamin Publishing.

Dehkhoda, A. (2011). Dehkhoda Dictionary. Tehran University Publication.

Denzin, N. \& Lincoln, Y. S. (1994). The HandBook of Qualitative Methods. Thousand Oaks, CA: Sage.

Denzin, N. \& Yvonna, S. L. (1994). The Sage Handbook of Qualitative Research, Second Edition. London: Sage Publication Ltd.

Fairclough, N. (1989). Language and Power (2nd Ed.). London, UK: Longman.

Fairclough N. (1996). A reply to Henry Widdowson's Discourse analysis: a critical view". Language and Literature 5 (1): 49-56.

Fairclough, N. (1992). Discourse and social change. . Cambridge: Polity Press.

Grant, D. \& Hardy, C. (2004). Introduction: struggles with organizational discourse. Organization_Studies. 25 (1). 2004. 5-13

Guba, E. G., \& Y. S. Lincoln (1982), "Epistemological and Mythological Bases Naturalistic Inquiry, Educational Communicational and Technology Journal 30 (4), 233-252.

Kazemian, B., Behnam, B., \& Ghafoori, N. (2013). Ideational Grammatical Metaphor in Scientific Texts: a Hallidayan Perspective. International Journal of Linguistics, 4(4), 146-168.

Kazemian, B., \& Hahemi, S. (2014a). Nominalizations in Scientific and Political Genres: a Systematic Functional Linguistics Perspective, International Journal of Humanities and Social Sciences (IJHSS), 3(2), 211-228.

Kazemian, B., \& Hahemi, S. (2014b). Critical Discourse Analysis of Barack Obama's 2012 Speeches: Views from Systematic Functional Linguistics and Rhetoric. Theory and Practice in Language Studies (TPLS), 4(6), 1178- 1187. Doi: 10.4304/tpls.4.6.1178-1187.

Krefting, L. (1991). Rigor in Qualitative Research: The Assessment of Trustworthiness. The American Journal of OCCupClliol1al Therapy 45 (3), 214-222.

Mohammadi Amoli, M.R. (2011). Chagoor Song (Life and the poem of Mehdi Akhavan Sales). Tehran Publication.

Noor, M., Ali, M., Muhabat, F. \& Kazemian, B. (2015a). Systematic Functional Linguistics Mood Analysis of the Last Address of the Holy Prophet (PBUH). International Journal of Language and Linguistics. Special Issue: Critical Discourse Analysis, Rhetoric, and Grammatical Metaphor in Political and Advertisement Discourses. 4(1-1), 1-9). Doi: 10: 11648/j.ji11.s.2015030501.11.

Noor, M., Mustafa, R., Muhabat, F. \& Kazemian, B. (2015b). The Language of TV Commercials Commercials' Slogans: A Semantic Analysis. Communication and Linguistics Studies. 1(1), 7-12. Doi: 10.11648/j.cls. 20150101.12.

Nur, S. (2015). Analyzing of Interpersonal Metafunction in Public Speeches: a Case Study of Nelson Mandela's Presidential inauguration Speech. The International Journal of Social Sciences. 30(1), 52-63.

Zhou, Q. \& Kazemian, B. (2015). A Rhetorical Identification Analysis of English Political Public Speaking: John F. Kennedy's Inaugural Address: International Journal of Language And Linguistics. Special Issue: Critical Discourse Analysis, Rhetorical and Grammatical Metaphor in Political and Advertisement Discourses. 4(1-1), 10-16. Doi: 10.11648/j.ij11.s.2016040101.12. 